\title{
O Museu de Anatomia Veterinária da FMVZ- USP: Proposta e Análise de um Método Sistêmico e Modular de Planejamento e Ação
}

\author{
The Museum of Veterinary Anatomy of FMVZ-USP: \\ Proposal and Analysis of a Systemic and Modular Method \\ of Planning and Action
}

\section{RESUMO}

No dia 9 de setembro de 2012, a nova exposição de longa duração do Museu de Anatomia Veterinária da Faculdade de Medicina Veterinária e Zootecnia da Universidade de São Paulo completou dois anos de existência. Este período também é marcado pela implantação de uma nova estratégia de trabalho, caracterizada por uma metodologia sistêmica e modular de planejamento e desenvolvimento de ações no museu. Este artigo tem por objetivo apresentar uma estratégia de gestão para museus universitários, com resultados e perspectivas futuras. Com isso, esperamos compartilhar nossa experiência e contribuir para a reflexão sobre essa tipologia de museus e suas perspectivas de desenvolvimento.

Palavras-chave: Museu universitário. Divulgação científica. Gestão de museu.

\section{ABSTRACT}

On September 9th 2012 the new long-term exhibition of the Museum of Veterinary Anatomy, School of Veterinary Medicine and Animal Husbandry, completed two years. This period is also marked by the implementation of a new strategy of work, characterized by a systemic and modular methodology of planning and development of activities at the museum. This article aims to present a management strategy for university museums, its performance and future prospects. We hope to share our experience and contribute to the discussion and development of this typology of museums.

Keywords: University museum. Scientific dissemination. Management of museum. 
*Cabe frisar que não se trata de uma afirmação universal, aplicada a todos os museus, mas dirigida aos museus universitários, com atuação na formação de coleções, pesquisa, salvaguarda e comunicação.
**É importante ressaltar a iniciativa e o envolvimento do prof. dr. Vicente Borelli para a formação do núcleo inicial das coleções e do seu esforço para a criação e oficialização do MAV.

\section{INTRODUÇÃO}

No dia 9 de setembro de 2012, a exposição de longa duração do Museu de Anatomia Veterinária "Prof. Dr. Plínio Pinto e Silva” (MAV), da Faculdade de Medicina Veterinária e Zootecnia da Universidade de São Paulo, intitulada Dimensões do corpo: da anatomia à microscopia, completou dois anos de existência. Além de um espaço expositivo renovado, também foi inaugurada uma nova forma de trabalho. Trata-se de um novo método de planejamento que tem como objetivo principal a implantação, dinamização e articulação das ações especialmente projetadas para este museu. A nova gestão, nesta data comemorativa, busca aqui refletir e apresentar os resultados do novo sistema de trabalho adotado, compartilhando sua experiência e projetando, com maior precisão, suas perspectivas futuras.

A ideia de uma instituição voltada à divulgação científica [9] tem norteado a missão do MAV. Nessa perspectiva, a atual exposição de longa duração se constituiu tanto centro irradiador da nova metodologia de trabalho quanto pilar central de todas as ações planejadas e em desenvolvimento. Diferentemente de gestões em museus que comumente atuam na divulgação científica - cujas linhas de estudo, pesquisa e curadoria são primordiais na definição das estratégias de trabalho -, para o Museu de Anatomia Veterinária da FMVZ-USP a comunicação museológica passou a ocupar papel central na sistematização dos seus trabalhos, orientando a salvaguarda, a pesquisa e suas ações educativas*. Isso decorre, de forma equivalente, tanto de uma característica determinada pelas circunstâncias atuais do museu, quanto de uma clara opção estratégica de trabalho. Veremos a seguir os desdobramentos desta estratégia que, num primeiro momento, parece inverter o sentido do fluxo lógico de trabalho em um museu, e os resultados obtidos nestes dois anos de experimento, em que a exposição ocupa papel central nas ações do MAV.

\section{HISTÓRICO}

Dos pontos de vista histórico e tipológico, o Museu de Anatomia Veterinária da FMVZ USP pertence à linhagem dos museus de História Natural, mas que se especializou no ramo dos museus de Anatomia Comparada e no sub-ramo da Anatomia Veterinária [7]. Suas coleções são caracterizadas por sua origem biológica (peças anatômicas de animais) e pelas técnicas de conservação (maceração, desidratação, diafanização, fixação em formaldeído, glicerinação, injeção de látex e taxidermia).

O MAV foi criado oficialmente em 1984 a partir da institucionalização das coleções de peças anatômicas existentes na faculdade resultantes dos estudos desenvolvidos por professores, servidores e alunos para as aulas práticas da disciplina de Anatomia** Trata-se de um caso exemplar de museu universitário, pertencente a uma instituição de ensino, pesquisa e extensão, constituído por coleções de pesquisa [6]. Suas ações envolvem a formação de coleções representativas [10], preparação de peças biológicas por meio do desenvolvimento de técnicas específicas, produção de coleções didáticas, salvaguarda do acervo e o ensino da Medicina Veterinária com ênfase na Anatomia. A difusão científica no museu ocorre por meio das coleções museológicas apresentadas 
em sua exposição e de projetos educativos. Há vinte e oito anos o MAV atua neste campo, com significativas variações no cumprimento de suas metas ao longo deste tempo.

Na sua trajetória mais recente - para acompanhar o deslocamento da nova sede da Faculdade de Medicina Veterinária e Zootecnia da USP dentro da Cidade Universitária “Armando de Salles Oliveira" -, entre 2004 e 2005, o MAV passou por uma traumática mudança de endereço, o que resultou em perda de exemplares de suas coleções, de recursos expositivos e, consequentemente, de visitantes. Entre 2004 e 2008, ficou fechado para visitação. Esse processo também resultou na organização de uma exposição, em 2008, num espaço pouco apropriado para o desempenho de suas funções museológicas. Foi um período de muito desgaste para o museu como um todo ${ }^{* * *}$.

Contudo, em 2010, no contexto de esforço administrativo da direção da FMVZ-USP e da Pró-Reitoria de Cultura e Extensão Universitária da USP para a recuperação do vigor das suas atividades, o MAV teve sua equipe ampliada, traçou novos planos, recebeu investimentos e passou por uma adaptação em sua estrutura física e organizacional.

Nestes dois últimos anos foi implantada uma nova e estratégica dinâmica de trabalho, centrada na sistematização do seu planejamento e de suas práticas, baseadas em programas de trabalho que se conectam entre si sob a lógica de um sistema de ações $m u$ seológicas [1]; tal estratégia está estruturada na atual exposição de longa duração. Nesta gama de atuação preservacionista, daremos enfoque ao aspecto gerencial da extensão universitária praticada pelo MAV, representada aqui pela perspectiva da comunicação museológica, impulsionadora e motivadora do planejamento e das ações de um museu em transformação.

\section{MATERIAIS E MÉTODOS}

Para o início da aplicação de um sistema de ações museológicas, foi realizado, primeiramente, um reconhecimento do museu e, posteriormente, a implantação de um Programa de Trabalho, tendo este a função de sistematizar e dar coesão ao conjunto de diferentes atividades do museu.

A introdução do novo método de trabalho passou pela execução de um diagnóstico museológico [4]. Este instrumento de trabalho foi a primeira ação desenvolvida pela nova gestão e teve o objetivo de evidenciar os aspectos qualitativos e quantitativos do museu, mapeando suas potencialidades e imperfeições. O diagnóstico museológico foi uma estratégia pontual, servindo como indicador e orientador para ações iniciais. Ele destacou quatro aspectos inerentes ao MAV e às pretensões de implantação de um sistema de ações museológicas segundo práticas profissionais contemporâneas [2]: o perfil institucional; o histórico de ações; as potencialidades; as irregularidades.

O diagnóstico museológico foi uma estratégia de reconhecimento geral das características e condições em que o museu se encontrava naquele momento, permitindo o início mais seguro do planejamento de novas ações. Trata-se da produção do retrato de um momento institucional. Ele foi desenvolvido entre os meses de julho e agosto de 2010 pela própria equipe do MAV e sob a coordenação dos novos gestores através das seguintes etapas de trabalho:

\author{
***Um dos indicadores de \\ declínio diz respeito à queda \\ brusca do número de visitantes \\ ao museu. Relatórios internos \\ apontam que, no início de \\ 2000, o MAV tinha um público \\ anual de, aproximadamente, \\ 14 mil visitantes e,em 2009, \\ recebeu apenas cerca de 3,5 \\ mil visitantes. Com grande \\ esforço, levará muitos anos \\ para ser alcançado novamente \\ o número de visitantes do \\ início de 2000, o que nos \\ faz pensar sobre as drásticas \\ consequências da mudança \\ de endereço e do fechamento \\ público de um museu.
}


${ }^{\star \star \star \star \star}$ Ainda que não aprovado pelas instâncias superiores da USP, o museu possui texto redigido e discutido pelo Conselho Técnico Administrativo da FMVZ. Atualmente, o regimento está em processo de atualização dentro da nova realidade universitária. Mas o que mais importava no momento da elaboração do diagnóstico era a identificação da intenção regimental e a localização do percurso traçado para este fim pela administração da faculdade para o museu.

$\star * \star \star \star$ No Brasil, além do MAV, existem mais cinco museus em atividade dessa tipologia, a saber: Museu de Anatomia Comparada da Universidade Federal da Bahia; Museu de Anatomia Animal Comparada da Universidade Federal de Viçosa; Museu Itinerante de Anatomia Animal da Universidade do Vale do São Francisco; Museu de Anatomia Comparada da Universidade Federal Rural de Pernambuco; Museu de Anatomia Veterinária da Universidade de Brasília.

$\star \star \star \star \star \star A$ Fundação Parque Zoológico de São Paulo e a Secretaria de Meio Ambiente de São Paulo têm sido os mais importantes e principais parceiros na doação de exemplares de animais silvestres, permitindo a diversificação e enriquecimento das coleções do museu.
1. Etapa, análise da estrutura administrativa;

2. Etapa, análise de documentos históricos;

3. Etapa, levantamento preliminar do acervo (dados informativos, quantitativos e estado de conservação);

4. Etapa, análise das estratégias adotadas em diferentes momentos históricos, em diferentes contextos vividos pelo museu;

5. Etapa, avaliação da estrutura física e de recursos humanos.

Após o cumprimento destas cinco etapas foi possível identificar o MAV como um museu universitário de pequeno porte, com proposta de um regimento próprio ${ }^{* * * *}$, portador de ricas e diversificadas coleções de pesquisa, com vocação educativa na Medicina Veterinária. Mais precisamente, foi possível defini-lo como um museu especializado na formação de coleções, salvaguarda, pesquisa e divulgação dos conhecimentos referenciais sobre a Anatomia de Animais.

Concluímos se tratar de um museu de pequeno porte em função da dimensão do seu acervo (aproximadamente 1,1 mil peças), do edifício ( $475 \mathrm{~m} 2$ ), da equipe (cinco servidores) e do público visitante (em 2010, cerca de 3,5 mil visitantes). O resultado do diagnóstico evidenciou o seu grande potencial: o acervo [3].

Embora estivesse com as informações documentais desatualizadas, foi possível constatar a riqueza da representatividade da Medicina Veterinária e o valor educativo das coleções do MAV. O seu acervo o torna singular dentre os existentes em território nacional.

Não há muitos museus dessa tipologia no Brasil e todos são vinculados a instituições universitárias de Medicina Veterinária ${ }^{* * * *}[5]$. No entanto, o acervo se mostrou extremamente rico e diversificado, com importantes exemplares para a compreensão e o ensino na área como um todo, mas em especial à Anatomia de Animais. Além do acervo constituído, existe a possibilidade de incremento dessas coleções por meio da associação com os laboratórios existentes na faculdade, permutas com museus com coleções zoológicas e, principalmente, doações de carcaças de animais oriundas de diferentes zoológicos de São Paulo *****. A representatividade de espécies, espécimes, seções de exemplares, órgãos, seções de órgãos e de técnicas de conservação é ímpar dentre os museus desta tipologia no Brasil. Este é o mais alto valor do museu apontado pelo diagnóstico: a exclusividade de seu acervo (Figura 1, Figura 2 e Figura 3).

Figura 1 - Articulações desidratadas de membros anteriores de Equino. Foto: Ronaldo Aguiar, ago. 2010. Fonte: Acervo MAV FMVZ-USP.

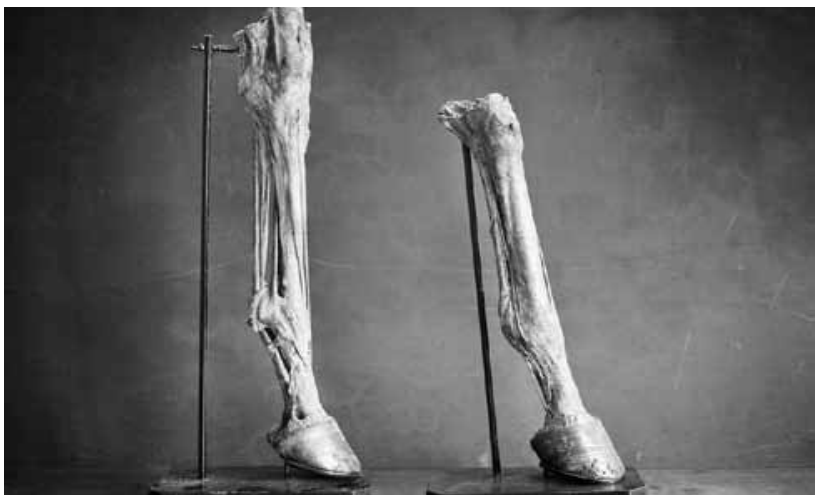




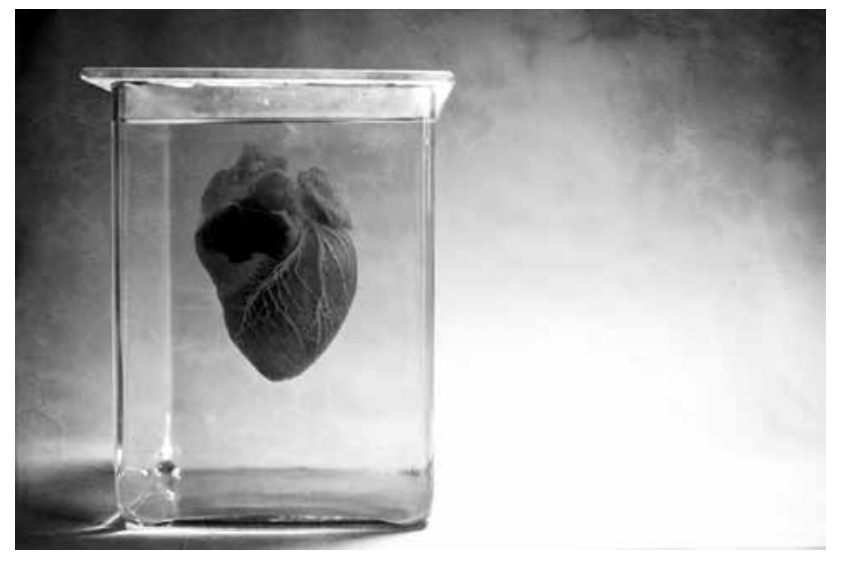

Figura 2 - Coração canino

fixado em formol. Foto:

Ronaldo Aguiar, ago. 2010.

Fonte: Acervo MAV FMVZ-USP.

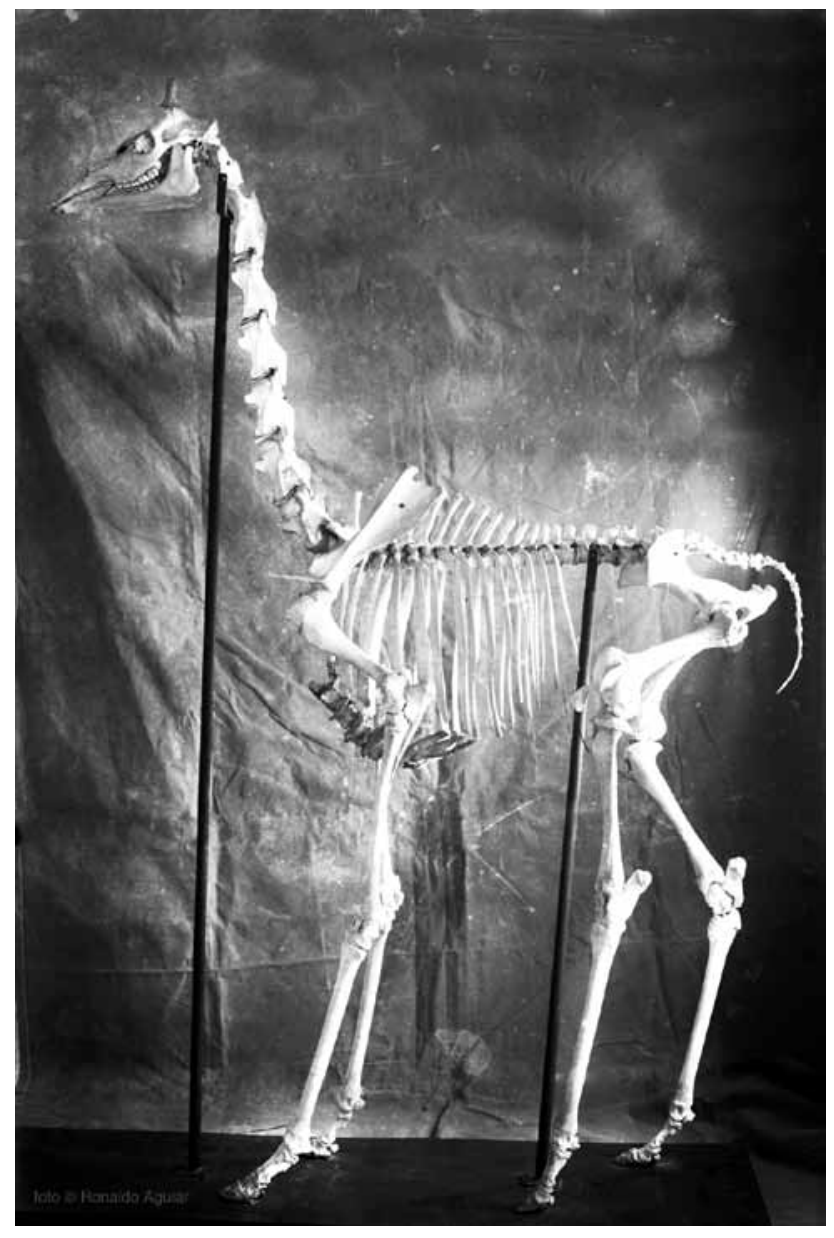

Figura 3 - Osteologia de um filhote de girafa, preparada por meio da maceração. Foto: Ronaldo Aguiar, ago. 2010. Fonte: Acervo MAV FMVZ - USP. 
O diagnóstico destacou a ausência de um plano de comunicação, mas, sobretudo, a precariedade nas estruturas físicas do MAV: o museu possui uma área muito pequena para o desempenho de suas atribuições; o acervo está comprimido no espaço, não havendo reserva técnica; precário espaço para preparação de peças e sem área administrativa. A exposição existente em 2010 não possuía um plano expositivo, muito menos um roteiro de visitação, os objetos não estavam devidamente identificados e não havia um projeto educativo. Em resumo, o diagnóstico aplicado ao MAV mostrou um dado positivo e dois negativos - o acervo, o edifício e a comunicação museológica, respectivamente.

A partir deste resultado - como reconhecimento do território - foi possível traçar com maior clareza e segurança o novo caminho para a gestão do museu. Ele foi estruturado em três etapas temporais, sendo elas:

1. Curto prazo (dois meses): adequações mínimas e essenciais no edifício; criação de uma imagem para o museu; montagem de nova exposição; criação e disponibilização de nova página eletrônica e início da implantação de um sistema de ações integradas.

2. Médio prazo (dois anos): aperfeiçoamento da exposição; desenvolvimento do projeto educativo; atualização da documentação do acervo; aumento ordenado de exemplares nas coleções; implantação do regimento; desenvolvimento de um plano museológico e elaboração de um projeto arquitetônico para o novo museu.

3. Longo prazo (cinco anos): construção de um novo edifício; implantação do Museu de Medicina Veterinária da FMVZ-USP e início de um novo ciclo de atividades.

Para sanar as questões emergenciais foram feitos ajustes essenciais na edificação, tais como: manutenção no telhado; pintura nas paredes, no piso e no teto; reparos elétricos e instalação de divisórias de ambientes. Paralelamente, foi desenvolvida uma proposta de comunicação museológica com base na criação de uma marca para o museu e de um projeto expositivo. Este conjunto de ações propiciou o funcionamento minimamente adequado. Como resultado deste processo surgiu a exposição intitulada Dimensões do corpo: da anatomia à microscopia, aberta ao público dois meses após o início do diagnóstico.

O projeto da nova exposição reorganizou o acervo existente, dentro do espaço disponível, a partir de um roteiro estruturado em seis módulos expositivos, a saber: "A FMVZ da USP e sua história”; "O que é Anatomia Comparada”; "Origem e diversidade das espécies"; "Anatomia dos órgãos e sistemas"; "Osteologia e Morfologia”. O projeto expográfico partiu do reaproveitamento do mobiliário expositivo, mas no contexto de uma nova identidade visual, desdobrada na comunicação do museu a partir de uma logomarca ( Figura 4, Figura 5 e Figura 6). 


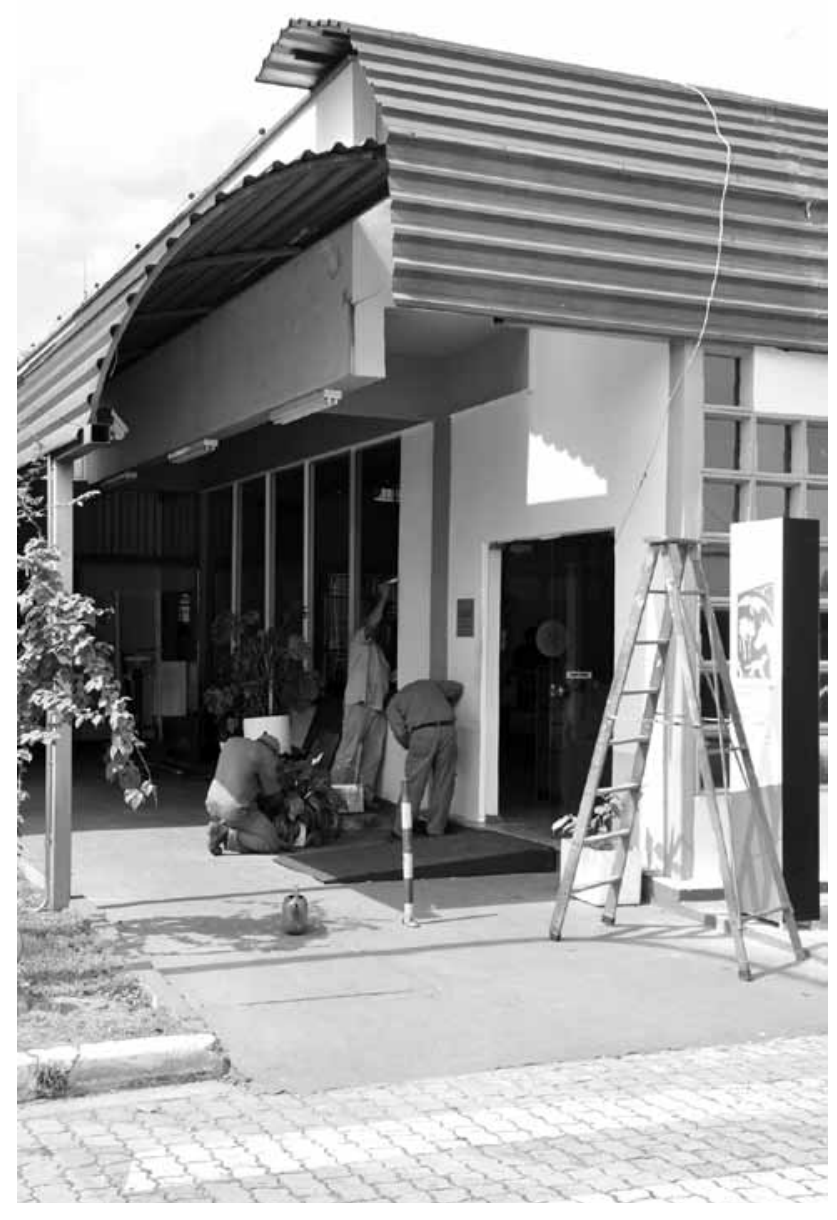

Figura 4 - Reparos na

edificação do MAV. Foto:

Maurício Cândido da Silva,

set. 2010. Fonte: Acervo MAV

FMVZ-USP.

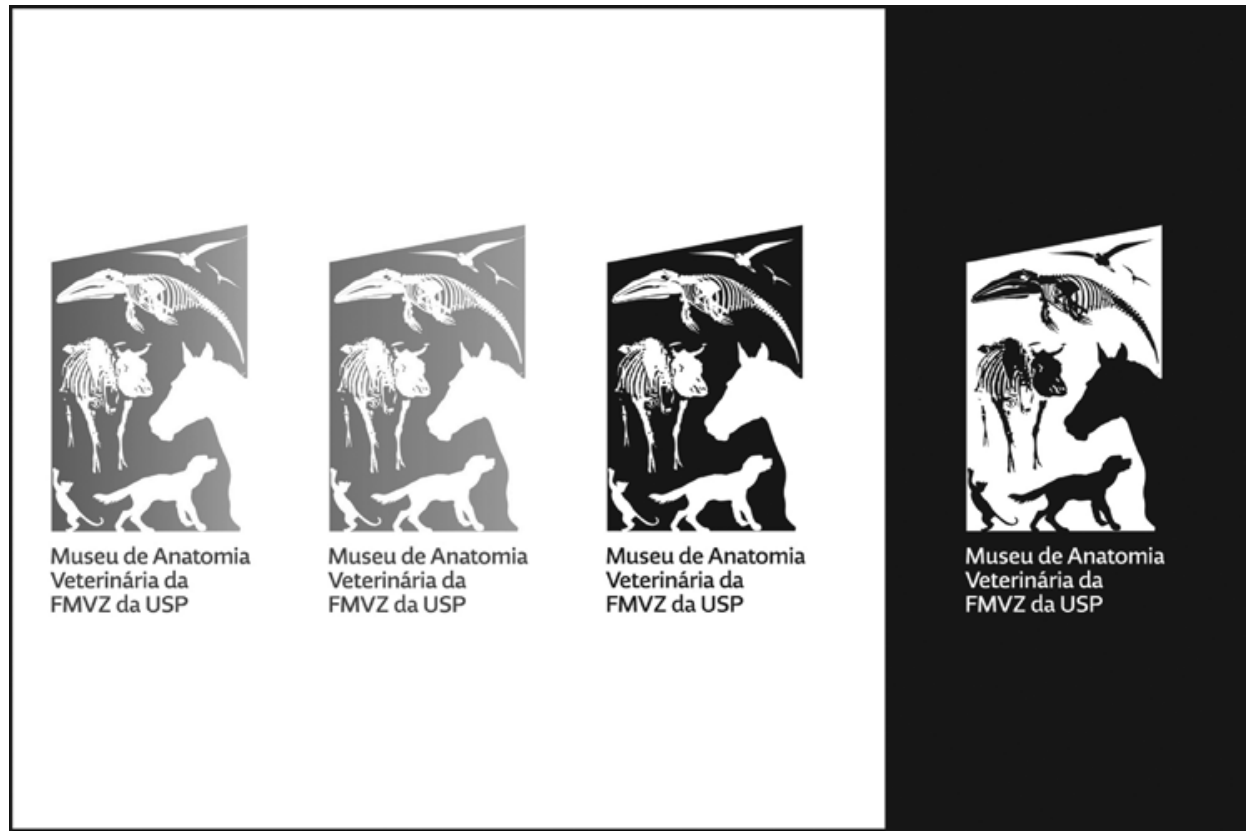

Figura 5 - Logomarca desenvolvida por Danilo Leite, da Dfuse Design para - MAV, a partir de programa desenvolvido por Maurício Cândido da Silva,

set. 2010. 
Figura 6 - Plano com roteiro expositivo desenvolvido para a exposição de longa duração do Museu de Anatomia Veterinária, ago. 2010.

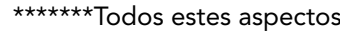
foram enumerados e detalhados em um documento intitulado Programa para projeto arquitetônico do novo prédio para o Museu da FMVZ da USP.

\section{Roteiro Painéis}

T1- Totem externo, com localização do MAV.

P1- Painel com texto de abertura da exposição e ficha técnica.

P2- Painel com título, texto e imagem sobre a FMVZ da USP e sua história.

P3- Painel com título, texto e imagem sobre anatomia comparada.

P4- Painel com título, texto e imagem sobre origem e diversidade de animais.

P5- Painel com sub-título, texto e imagem sobre diversidade de cetáceos.

P6- Painel com sub-título, texto e imagem sobre origem de cetáceos.

P7- Painel com sub-título, texto e imagem sobre origem e diversidade de aves.

P8- Painel com título, texto e imagem sobre os sistemas orgânicos.

P9- Painel com título, texto e imagem sobre os osteologia e morfologia.

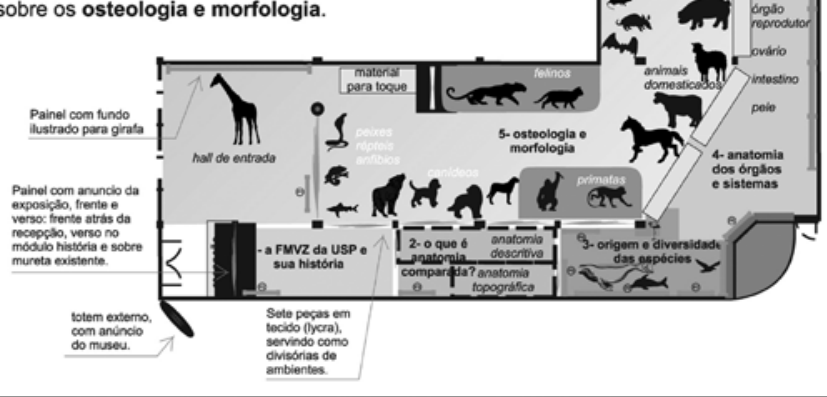

Embora seja uma exposição de longa duração, ela possui um caráter transitório, pois as perspectivas gerais para o MAV são mais complexas e promissoras: uma nova estrutura administrativa e operacional para o museu, incluindo um novo edifício, para o desempenho completo e adequado de suas atribuições. A transposição de um Museu de Anatomia Veterinária para um Museu de Medicina Veterinária - incluindo os diversos campos desta ampla área do conhecimento - vai além da Anatomia. Dessa forma, as ações desenvolvidas em médio prazo devem claramente servir às ações de longo prazo, com caráter de maior consistência, durabilidade e definição do museu, incluindo a transformação de seu pequeno porte para médio. Essa caracterização foi fundamental na modelização do método empregado e na modulação de um Programa de Trabalho, sustentáculo do sistema de ações museológicas.

Levando em conta o histórico do MAV e as perspectivas futuras, a metodologia de trabalho implantada adquiriu assim um caráter transitório, dinamizando o museu e o preparando para as desejadas transformações. $O$ planejamento para o novo edifício deveria incluir novas e modernas instalações físicas, tais como laboratórios de preparação de peças, reservas técnicas, salas expositivas especialmente desenhadas, recursos expográficos atualizados, acessibilidade total, espaços educativos e recursos humanos capacitados para o pleno desempenho de suas atividades ${ }^{* * * * * * *}$. Em função disso, $o$ sistema de ações museológicas adquiriu um caráter tanto experimental para o presente momento quanto basal para o futuro. Disso resultou uma metodologia de planejamento e ações dentro de Programas de Trabalho modulares, permitindo a inclusão ou remoção de novas ações sem a necessidade da completa mudança do sistema de trabalho, que adotou a exposição como pilar central de seu funcionamento.

Metodologicamente, sua definição é de um sistema de inter-relação entre Programas de Trabalho que compõem a rede de ações do Museu de Anatomia Veterinária. Trata-se de uma metodologia que visa a garantir a conexão de todas as ações que envolvem um museu especializado na formação de coleções, salvaguarda, pesquisa e divulgação dos conhecimentos 
referenciais sobre a Anatomia de Animais. Por sua vez, os Programas de Trabalho são definidos como módulos unitários contentores de ações correlacionadas. Neste momento foram definidos cinco grupos, sendo eles: Programa de Comunicação (central); Programa Educativo; Programa de Acervo; Programa de Treinamento; Programa de Inovação. $\mathrm{O}$ objetivo dessa estratégia é gerar a melhor funcionalidade de uma estrutura organizada, tal qual o sistema de um organismo vivo, especialmente para este museu. Uma visão esquemática e sucinta pode ser observada abaixo (Figura 7 ).

Esta estratégia tem sido desenvolvida nestes dois anos da nova gestão do MAV. Ela é a base metodológica de trabalho, cujos princípios são norteados pela orientação sistêmica das ações programáticas de um museu universitário, pertencente a uma unidade de ensino e pesquisa, com uma missão pautada pela formação de coleções, salvaguarda, pesquisa e comunicação, mas, sobretudo, pela preservação da Anatomia Veterinária como área de saber e como acervo.

\section{RESULTADOS}

Algumas das ações planejadas tiveram resultados parciais. No entanto, é possível considerar que a estratégia de trabalho estruturada por programas modulares tem se mostrado apropriada para a realidade do Museu de Anatomia Veterinária da FMVZ USP com indicadores satisfatórios. Como resultado de um diagnóstico e de uma visão sistêmica das ações desenvolvidas no museu, os Programas de Trabalho organizam em grupos equivalentes as diferentes estratégias de musealização da Anatomia Veterinária, orientando os projetos presentes e as perspectivas futuras.

Os resultados da implantação do novo sistema de trabalho, entre julho de 2010 e setembro de 2012, levam em consideração o papel central de sua exposição de longa duração,

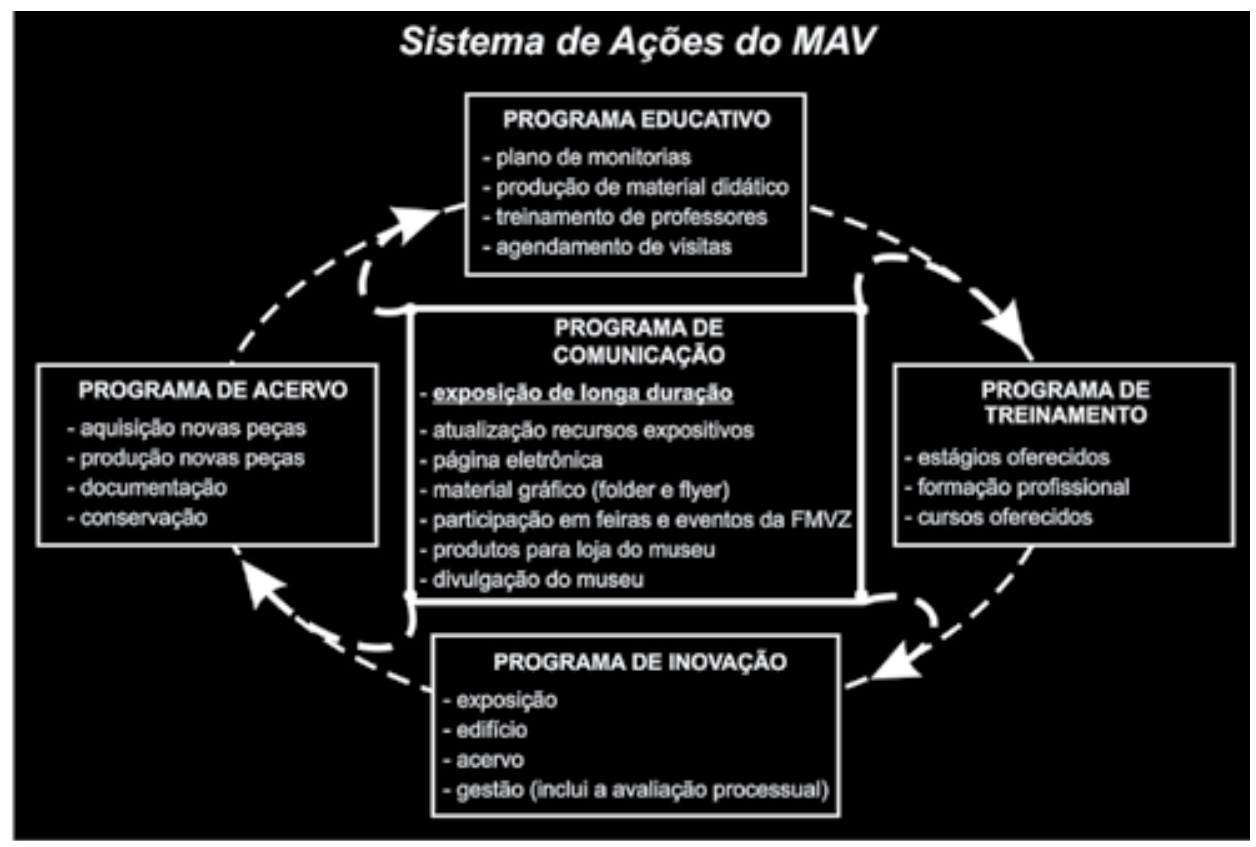

O Museu de Anatomia Veterinária da FMVZ-USP: Proposta e Análise de um Método Sistêmico
Figura 7 - Esquema do sistema de ações do MAV, centrado na exposição de longa duração, destacando os Programas de Trabalho. Diagramação: Maurício Cândido da Silva, jan. 2012 
$\star \star \star \star \star \star \star \star \star \star$ Segundo o Código de Ética do Comitê Internacional dos Museus, revisado na $21^{\text {a }}$ Assembleia Geral do ICOM, realizada em Seul, Coreia do Sul, em 8 de outubro de 2004, "os museus são instituições permanentes, sem fins lucrativos, a serviço da sociedade e do seu desenvolvimento, abertas ao público, que adquirem, preservam, pesquisam, comunicam e expõem, para fins de estudo, educação e lazer, os testemunhos materiais e imateriais dos povos e seus ambientes" [8] (grifo nosso).

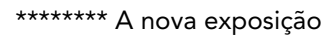
foi inaugurada no dia 11 de setembro de 2010 e, para a sua preparação o museu ficou fechado durante três meses, 0 que influenciou na taxa anual de visitação daquele ano. sendo mensurados por indicadores quantitativos de cada um dos Programas de Trabalho. Será destacado, primeira e principalmente, o volume de visitantes recebido pelo museu neste biênio, devido não só ao papel central desempenhado pela exposição aberta à visitação, mas também por conta da assimilação do MAV como um serviço de extensão universitária, dada sua importância na socialização do conhecimento científico. Sendo assim, a sua função social é assumida como fundamento que justifica sua existência ${ }^{* * * * * * *}$. Esta definição é importante na medida em que auxilia na classificação do seu plano de ação.

Malgrado seu pequeno porte, apontam para a alta demanda e reais condições de crescimento do MAV o seu histórico, a possibilidade de crescimento de suas coleções, a especificidade e infrequência dessa tipologia de museu, bem como a crescente procura escolar e de interesse geral por informações sobre a Medicina Veterinária.

Essa perspectiva ganhou grande apoio administrativo não só por conta do seu mérito, mas também por conta da implantação da Praça dos Museus que passou a ser construída na Cidade Universitária (Figura 8). Fatores endógenos e exógenos estimulam o seu crescimento.

O seu público central é bastante definido, constituído por professores e alunos de diferentes níveis escolares - do Fundamental I até a pós-graduação -, com destaque para o Ensino Médio, que busca orientação para formação, e o Ensino Superior, nas áreas de Medicina Veterinária e Biociências, através de aulas práticas no museu.

Neste contexto de audiência, assimilando a divulgação cientifica como campo de atuação do MAV e a implantação de uma metodologia baseada em Programas de Trabalho, foi possível contar com uma estratégia mais definida de comunicação para os diferentes tipos de visitantes pertencentes ao seu campo de interesse. Foram agregados ao plano de comunicação materiais impressos e uma interface museu-público por meio de uma nova página eletrônica na internet, que cumprem a missão de divulgar e atrair visitantes ao museu. Reforçando o perfil institucional, as novas ações consolidaram a constituição do público de visitantes e usuários (Gráfico 1).

A avaliação dos resultados dessa estratégia revela um caminho que parece ser promissor, pois verificamos um significativo aumento no número de visitantes em 2011, comparado aos três anos anteriores (Gráfico 2 e Gráfico 3) ${ }^{* * * * * * * *}$. Os dados de 2012 ainda não estão finalizados, mas verificamos que de janeiro a setembro, o museu recebeu 5.178 visitantes. É possível afirmar este número ultrapassará a casa dos 6 mil, meta estipulada para este período. Ou seja, com a nova metodologia, em dois anos, foi possível aumentar a visitação ao MAV em mais de 70\%. 
Gráfico 1 Amostragem do perfil de visitante do MAV durante o ano de 2011.

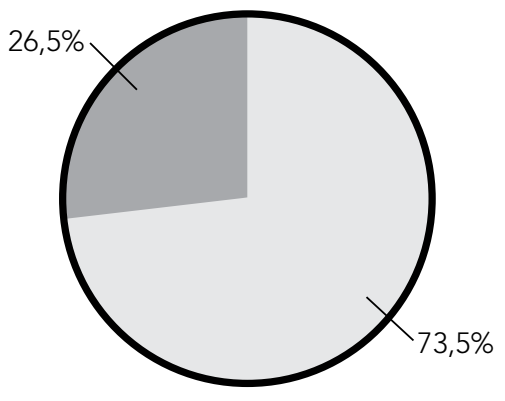

Grupos escolares

$\square$ Público espontâneo

Gráfico 2 Número de visitantes do MAV por ano.

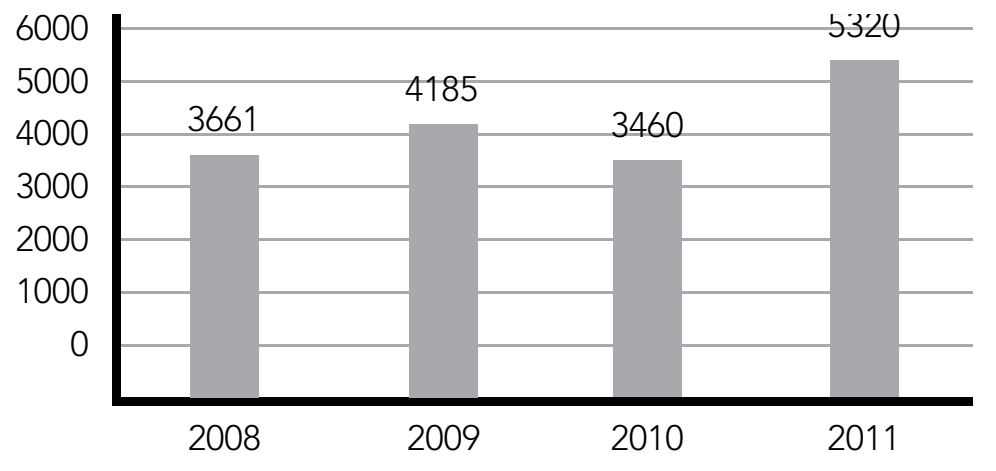


Gráfico 3 Variação percentual de visitantes ao MAV por ano.

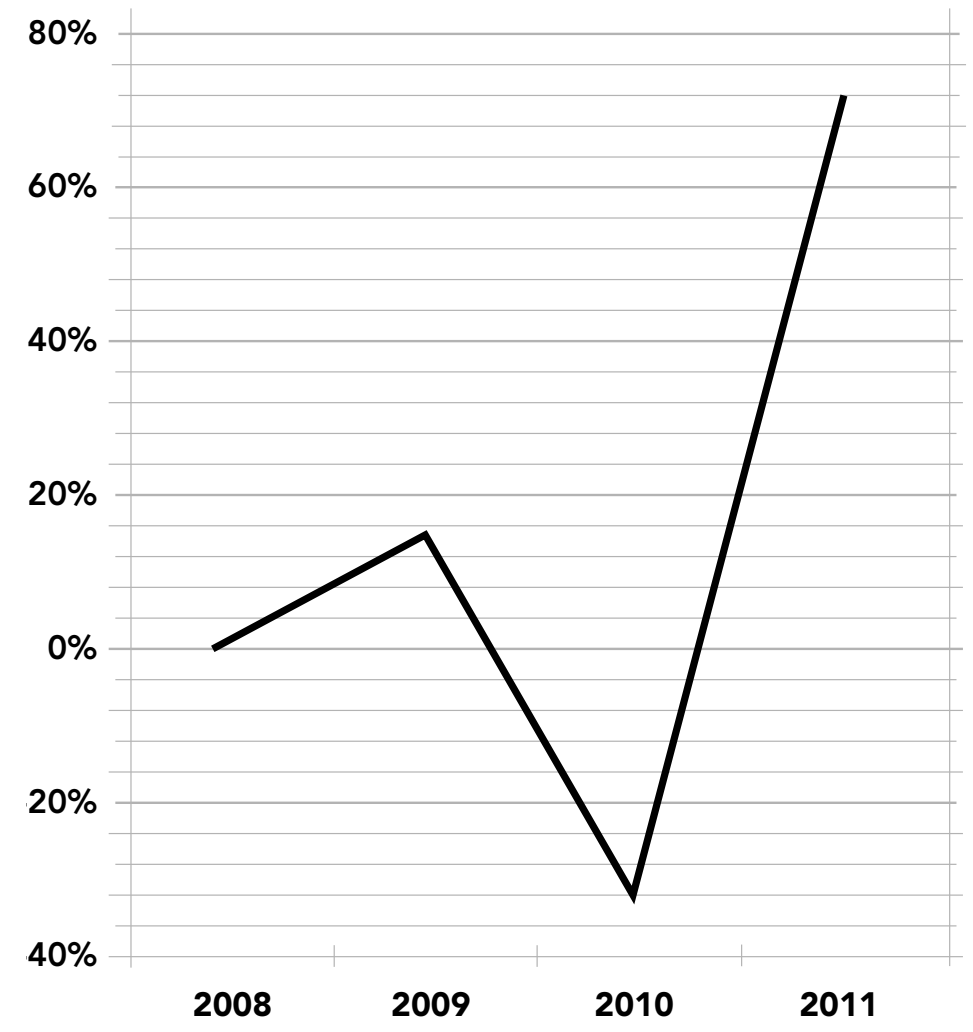

Isso não basta como um indicador de bons resultados, pois é necessário mensurar os diferentes aspectos de apropriação das informações apresentadas no programa de comunicação aos visitantes, principalmente junto aos professores que trazem seus alunos. Já demos início a esse processo e, em 2013, teremos mais elementos para a realização de uma avaliação mais completa. Além disso, desde maio de 2012, temos acompanhado de perto o desempenho da nova página eletrônica do museu, (<http:// www.mav.fmvz.usp.br $>$ ), inaugurada em 2010. Ainda que somente em língua portu-

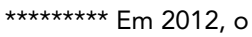
MAV participou de cinco feiras, sendo elas: Feira Internacional de Caprinos e Ovinos; Feira Internacional da Cadeia Produtiva de Carne; Feira de Profissões; Expocavalos e Semana Nacional de Ciência e Tecnologia. Essa participação corresponde à montagem de uma vitrina dentro do estande com exposição de exemplares do MAV, serviço de monitoria e distribuição de folhetos do museu. guesa, esta interface tem se mostrado extremamente eficaz, com média de 560 acessos mensais. É preciso disponibilizá-la em outros idiomas, inserindo assim o MAV nos processos de internacionalização estimulados pela própria administração universitária. Além destas duas categorias de visitantes e usuários, presenciais e virtuais, temos uma terceira, o público das feiras da FMVZ. Em 2012, atingimos a cifra de 30 mil visitantes indiretos .

A estratégia de Programas de Trabalho para as ações desenvolvidas no MAV também auxilia na equivalência da distribuição das ações preservacionistas, orientando as atividades em todos os cinco campos especificados nestes dois anos de existência. Além do Programa de Comunicação, que impulsionou o aumento do número de visitantes, obtivemos resultados satisfatórios em quase todas as ações nos demais programas, tal como apresentado na relação a seguir. 
1. Programa de Acervo: aquisição e produção de novas peças para o museu e início da atualização da documentação das coleções;

2. Programa Educativo: sistema de agendamento de visitas e plano de monitoria;

3. Programa de Treinamento: estágios oferecidos e formação profissional;

4. Programa de Inovação: exposição, edifício, acervo e gestão.

O resultado dessa metodologia de trabalho, caracterizada pela modulação dos Programas de Trabalho, permite afirmar que se trata de um adequado sistema de gestão para museus como o MAV, permitindo um amplo mapeamento das diferentes ações planejadas e executadas. Por meio deste mapeamento, é possível tornar o planejamento mais objetivo, mensurando os resultados e redirecionamento das ações, quando necessário. A maleabilidade da modulação tem se mostrado bastante adequada para um plano sistêmico que, por ser dinâmico, necessita de constantes ajustes, sem que haja perda de sua essência. Lembrando que o núcleo central definido para o MAV tem sido a formação de coleções, salvaguarda, pesquisa e divulgação dos conhecimentos referenciais sobre a Anatomia de Animais e que o Programa de Comunicação é o pilar central das ações programáticas, é possível afirmar, segundo os resultados obtidos até o presente momento, que a metodologia sistêmica de trabalho é bastante adequada.

\section{DISCUSSÃO}

Entendemos os resultados desse método como uma importante etapa para a transformação do Museu de Anatomia Veterinária da FMVZ-USP e para a realização de seu planejamento em longo prazo. Além do crescimento físico de seu porte, trata-se de uma mudança de procedimentos de trabalho, dentro de uma perspectiva de novos padrões, atuais e dinâmicos, visando à elaboração e a implantação de seu Plano Museológico e sua inserção nos parâmetros recomendados pela Política Nacional de Museus.

Nesse sentido, os resultados alcançados apontam para a importância da profissionalização e constante aprimoramento dos recursos humanos, da melhoria das instalações, do estabelecimento de um contínuo diálogo com os professores que levam seus alunos e a atualização da salvaguarda do acervo. Somente assim, na integridade destas ações, o MAV participará de forma incisiva no campo da preservação patrimonial. Nesse momento, estamos preparando o caminho para esta ação maior. Ou seja, é fundamental a existência de um Programa de Inovação atuante em todas as etapas do sistema de ações museológicas, de forma a garantir o progresso em todas as áreas de atuação do museu, impulsionando-o ao contínuo aprimoramento e na realização das suas funções de formação, salvaguarda, pesquisa e divulgação dos conhecimentos referenciais sobre a Medicina Veterinária. 


\section{CONCLUSÕES}

A estrutura modular vem permitindo ajustes e melhorias nos cinco Programas do MAV, sem alteração da proposta conceitual, seja como resultado de novas aquisições de acervo, aperfeiçoamento da linguagem expositiva, plano de monitorias, oferecimento de estágios ou mesmo por orientação da demanda pública. Neste último caso, o que tem contribuído de forma mais intensiva é a adequação do Programa Educativo do MAV ao currículo escolar, buscando um diálogo mais próximo com as escolas. Assim, podemos considerar que a difusão científica praticada tem os Programas de Trabalho como sistema neurológico e a exposição como sua coluna cervical de um corpo em estruturação. Essa tem sido a nossa estratégia para a renovação deste museu. Neste momento, estamos consolidando as estratégias adotadas e avançando na implantação dos programas planejados. Uma avaliação continuada apresentará um quadro de modificações e adições necessárias em nossos projetos.

É necessário considerar para a divulgação científica no MAV que toda exposição em um museu universitário tem por princípio a extensão cultural de suas pesquisas. A democratização do acesso a essa categoria de informação é uma bandeira que essa tipologia de museu carrega, pois sua função primordial é tornar público o conhecimento gerado nos laboratórios de pesquisa dentro das universidades. A exposição é um espaço dedicado à interatividade, multiplicidade de ideias e debates. $O$ possível resultado dessa experiência é o exercício da cidadania, no qual o sujeito (visitante) tem a oportunidade de se apropriar de um conhecimento científico e aplicá-lo ao seu cotidiano. Como um museu especializado na formação de coleções, salvaguarda, pesquisa e divulgação dos conhecimentos referenciais sobre a Anatomia de Animais, o MAV aborda aspectos relacionados à saúde dos animais e das próprias pessoas, estimulando o visitante a refletir e intervir nos processos de reconhecimento do corpo e seu cuidado.

\section{REFERÊNCIAS BIBLIOGRÁFICAS}

[1] BOTTALLO, M. Poder, cultura e tecnologia: o museu de arte e a sociedade de comunicação. Novos Olhares, São Paulo, v. 10, n. 19, p. 4-16, 2007.

[2] BOYLAN, P. J. (Org.). Como gerir um museu: manual prático. Paris: UNESCO, 2004. $259 \mathrm{p}$.

[3] CERAVOLO, S. M. Proposta de sistema de informação documentária para museus (SIDIM): a organização da informação para o Museu de Anatomia Veterinária da Faculdade de Medicina Veterinária e Zootecnia da Universidade de São Paulo. 1998. 125 f.. Dissertação (Mestrado em Biblioteconomia e Documentação) Escola de Comunicação e Artes, Universidade de São Paulo, São Paulo, 1998.

[4] DUARTE CANDIDO, M. Diagnóstico museológico: estudos para uma metodologia. In: SEMINÁRIO DE INVESTIGAÇÃO EM MUSEOLOGIA DOS PAÍSES DE LÍNGUA PORTUGUESA E ESPANHOLA, 1., 2010, Porto. Actas... Porto: Universidade do Porto, 2010. v. 3, p. 124-132. 
[5] INSTITUTO BRASILEIRO DE MUSEUS. Guia dos museus brasileiros. Brasília: IBRAM, 2011. 592 p.

[6] LOURENÇO, M. C. Between two worlds: the distinct nature and contemporary significance of university museums and collections in Europe. 2005. 432 f. 2 v. Tese (Doutorado)-Conservatoire National des Arts et Métiers, Paris, 2005.

[7] SILVA, M. C. da. Christiano Stockler das Neves e o Museu de Zoologia da Universidade de São Paulo. 2006. 274 f. Dissertação (Mestrado em Arquitetura e Urbanismo)-Faculdade de Arquitetura e Urbanismo, Universidade de São Paulo, São Paulo, 2006.

[8] UNESCO. International Council of Museums. Código de ética do ICOM para museus: versão lusófona. Tradução: Comitê Brasileiro e Comitê Português do ICOM. International Council of Museums: Comitê Brasileiro. São Paulo: Imprensa Oficial, 2009. 29 p.

[9] VOGT, Carlos (Org.). Cultura científica: desafios. São Paulo: EDUSP; São Paulo: FAPESP, 2006. $232 \mathrm{p}$.

[10] WITTLIN, A. S. The Museum: Its history and its tasks in education. London: Routledge \& K. Paul, 1949. 297 p. Ilustrado.

\section{AGRADECIMENTOS}

Agradeço a Marilúcia Bottallo pela cuidadosa revisão e comentários. Agradeço também aos professores e amigos Francisco Javier Hernandez Blazquez e José Antonio Visintin, pelo acolhimento, confiança e incentivo ao desenvolvimento deste importante Museu.

MAURÍCIO CÂNDIDO SILVA mestre e doutorando em Arquitetura pela Faculdade de Arquitetura e Urbanismo da Universidade de São Paulo (FAU-USP), especialista em Museologia e responsável pela seção de preparação e conservação de peças do Museu de Anatomia Veterinária da FMVZ-USP Av. Prof. Dr. Orlando Marques de Paiva, 87 - CEP 05508-27o - Cidade Universitária - São Paulo-SP - email:maumal@usp.br. 